\title{
Analysis of Coaxial Magnetic Gear with Low Gear Ratios for Application in Counter Rotating Systems
}

\author{
H. M. Shin and J. H. Chang* \\ Electrical Engineering Department, Dong-A University, Saha-gu, Busan 604-714, Korea
}

(Received 7 May 2015, Received in final form 8 June 2015, Accepted 8 June 2015)

\begin{abstract}
This paper describes the electromagnetic and mechanical characteristics of coaxial magnetic gear (CMG) with a low gear ratio. The analysis models are restricted to a CMG with a gear ratio of less than 2 . The electromagnetic characteristics including transmitted torque and iron losses are presented according to the variation of the gear ratio. The pole pairs of high speed rotor are chosen as 6,8 and 10 by considering the torque capability. As the gear ratio approaches 1, both iron losses on the ferromagnetic materials and eddy current losses on the rotor permanent magnets are increased. The radial and tangential forces on the modulating pieces are calculated using the Maxwell stress tensor. When the maximum force is exerted on the modulating pieces, the mechanical characteristics including stress and deformation are derived by structural analysis. In CMG models with a low gear ratio, the maximum radial force acting on modulating pieces is larger than that in CMG models with a high gear ratio, and the normal stress and normal deformation are increased in a CMG with a low gear ratio. Therefore, modulating pieces should be designed to withstand larger radial forces in CMG with a low gear ratio compared to CMG with a high gear ratio.
\end{abstract}

Keywords : coaxial magnetic gear, counter rotating system, low gear ratio, Maxwell stress tensor, radial force

\section{Introduction}

A counter-rotating propeller (CRP) is known as complex propulsion device with high efficiency. It produces thrust by spinning two propellers in the opposite direction $[1,2]$. In general, the rotational speed of the forward propeller is lower than that of the aft propeller and two propellers have a gear ratio of around 1.2 to 1.4 to increase propulsive efficiency in marine applications [3]. Furthermore, the counter rotating mechanism has been applied to the energy conversion devices used in wind power and gas turbine generation to improve the system efficiency. These applications also have a low gear ratio of 1 to $2[4,5]$. However, counter rotating devices driven by mechanical gear structure have some drawbacks including acoustic noise, mechanical losses and high maintenance cost as well as complex structure.

In contrast, a coaxial magnetic gear (CMG) has two counter rotating parts inherently and it has a contactless structure [6]. The use of a CMG instead of a mechanical

(C)The Korean Magnetics Society. All rights reserved.

*Corresponding author: Tel: +82-51-200-7735

Fax:+82-51-200-7743, e-mail: cjhwan@dau.ac.kr drive system would significantly mitigate, or in some cases eliminate, the drawbacks noted above. Many researchers have studied the improvement of the transmitted torque of CMG with relatively high gear ratio [7-10]. However, the characteristics and performances of CMG with a low gear ratio of 1 to 2 have not been reported yet in detail.

This paper analyzes the electromagnetic and mechanical characteristics of CMG models with gear ratios of less than 2. Each model has the same dimensional and material properties except for the number of pole pairs on the rotors and the corresponding number of modulating pieces. Torque characteristics and iron losses are compared according to the variation of the gear ratio and number of pole pairs in the high speed rotor. The magnetic forces acting on each modulating piece are calculated using the Maxwell stress tensor. The resulting maximum normal and shear stresses, and corresponding deformations are compared at the modulating pieces receiving the largest radial and tangential forces. The magnetic gear performances for the variants are analyzed with electromagnetic and mechanical finite element analysis. 


\section{Basic Principle of Coaxial Magnetic Gear}

Fig. 1 shows the structure of a basic CMG. It consists of an inner high speed rotor, outer low speed rotor, and the modulating pieces [6]. The magnetic flux produced by the permanent magnets (PMs) on each rotor is modulated to have appropriate space harmonics associated with PM rotors. When each part of CMG satisfies the following condition, it produces a magnetic gearing effect.

$$
p_{l}=n_{s}-p_{h}
$$

where $p_{h}$ is the number of pole pairs on a high speed rotor, $p_{l}$ is the number of pole pairs on a low speed rotor and $n_{s}$ is the number of modulating pieces, respectively. If the modulating pieces are fixed, the gear ratio, $G$, between two rotors can be expressed as follows.

$$
G=\frac{\left|p_{\text {active }}-n_{s}\right|}{p_{\text {active }}}=\frac{p_{\text {passive }}}{p_{\text {active }}}
$$

where $p_{\text {active }}$ and $p_{\text {passive }}$ are the number of pole pairs of the magnetically active and passive rotor, respectively. Magnetically active rotor is a rotating part connected to the magnetic gear input. It can be an inner rotor for speed reduction application or it can be an outer rotor for speed increase application. Magnetically passive rotor is the other rotating part connected to the magnetic gear output. Since the number of modulating pieces is always greater than the number of pole pairs of each rotor, the numerator in (2) has a negative sign regardless of whether the magnetically active part is the high speed or low speed rotor. This means that the CMG has a counter rotating mechanism in itself. The parameters for the analyzed magnetic gear are listed in Table 1 . The material of the rotor core and modulating pieces is non-oriented electrical steel with a thickness of $0.35 \mathrm{~mm}$ having iron loss of 4.4 $\mathrm{W} / \mathrm{kg}$, and $\mathrm{PM}$ is neodymium magnet.

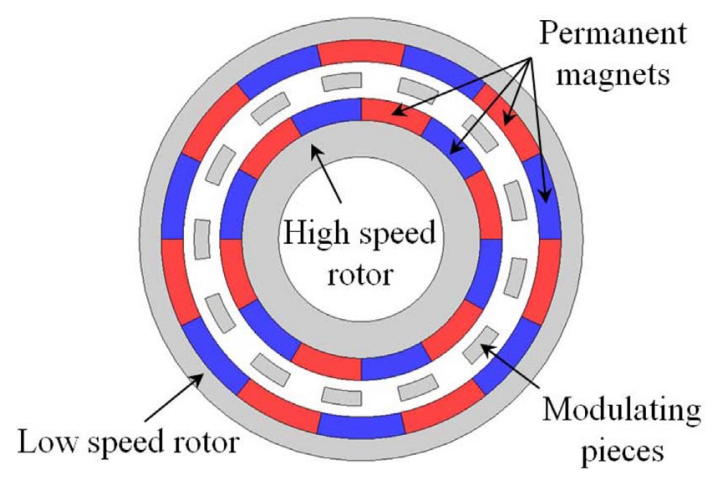

Fig. 1. (Color online) Structure of coaxial magnetic gear.
Table 1. Specifications of the analysis models.

\begin{tabular}{lc}
\hline \hline Parameters & Values \\
\hline Number of pole pairs on high speed rotor & $6,8,10$ \\
Gear ratio, $G$ & $1.1 \sim 1.9$ \\
Outer diameter [mm] & 117 \\
Axial length [mm] & 30 \\
Air gap length [mm] & 1 \\
PM radial thickness [mm] & 6 \\
Remanence of PM [T] & 1.25 \\
\hline
\end{tabular}

\section{Characteristics of Torque}

Fig. 2 shows the pull out torque on both rotors as the variation of pole pairs of high speed rotor for the same gear ratio of 1.5. When the CMG models have even number of pole pairs on a high speed rotor, the gear ratio of 1.5 can always be derived by selecting the number of pole pairs on a low speed rotor as one and half times of the number of pole pairs on a high speed rotor. Even though the gear ratio is same, the magnetic gear has poor torque capability when the number of pole pairs on a high speed rotor approaches 2 . This is due to the significant saturation of ferromagnetic materials caused by a small number of pole pairs on both rotors. In contrast, the pull out torque is also decreased as increasing the number of pole pairs. Different from the magnetic saturation, the flux from one pole leaks out considerably to the adjacent poles in this case. Thus, except for both ends, the pole pair of high speed rotor, $p_{h}=6,8,10$ are considered for the characteristic comparison of the magnetic gears having low gear ratio.

Fig. 3 shows the pull out torque on both rotors with the variation in gear ratio for the selected pole pairs of the high speed rotor. In the case of high speed rotors, the pull

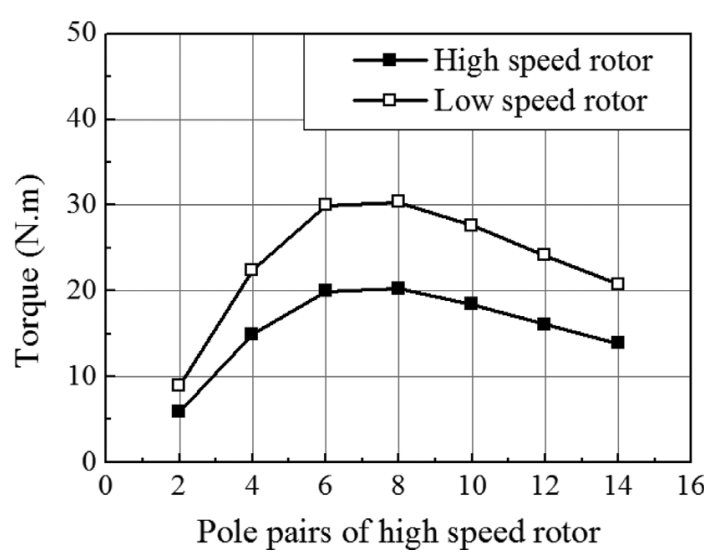

Fig. 2. Pull out torque on both rotors for the different pole pairs of high speed rotor at a gear ratio 1.5. 


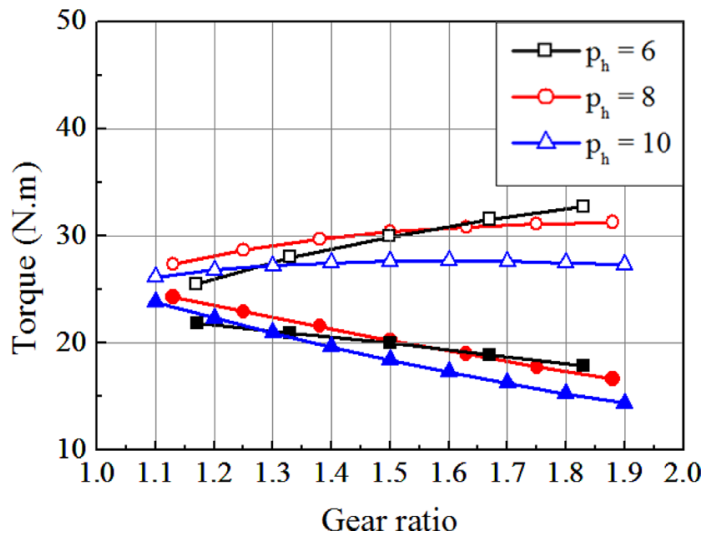

Fig. 3. (Color online) Pull out torque on both rotors with the variation of gear ratio for the different pole pairs of high speed rotor.

out torque is increased as the gear ratio is decreased. However, the pull out torque on the low speed rotors is reduced as the gear ratio is getting closer to 1 . In addition, the pull out torque varies with the number of pole pairs of the high speed rotor. In CMG having six pole pairs on the high speed rotor, pull out torques on both rotors are larger than those of the other CMG models when the gear ratio is close to 2. However, when the gear ratio is getting closer to 1 , the pull out torque rapidly decreases in low speed rotor. In $p_{h}=10$ case, the pull out torque is smaller than those of the other CMG models and it changes a little as the variation of gear ratio at the low speed rotor.

The torque ripple on a CMG is closely related to the least common multiple of the number of pole pairs on the rotors and the number of modulating pieces. The high speed rotor in a CMG has fewer pole pairs compared to the low speed rotor. Thus, in general case, the torque ripple on high speed rotor is of importance in the torque characteristics. Table 2 shows the comparison of torque ripple on the high speed rotor with the variation of gear ratio and number of poles. It can be seen that the least common multiple, $N_{c}$ is the dominant factor influencing torque ripple regardless of gear ratio. When selecting an appropriate gear ratio, it is therefore highly desirable to consider a number of poles and modulating pieces to maximize the least common multiple between them.

\section{Characteristics of Iron Loss}

The magnetic gear itself has no active parts to transmit power but it has losses on the ferromagnetic material and PM due to the variation of magnetic flux. Fig. 4 shows the iron losses on the ferromagnetic materials with the variation of gear ratio for the different pole pairs on a high speed rotor at a constant rotational speed of 1,000 $\mathrm{rpm}$. When the gear ratio is close to 2, the CMG models having ten pole pairs on high speed rotor has relatively small iron losses because it has a many number of PMs on both rotors and remains relatively unsaturated condition on the back yokes as well as modulating pieces. In contrast, as the gear ratio is getting smaller, the ferromagnetic

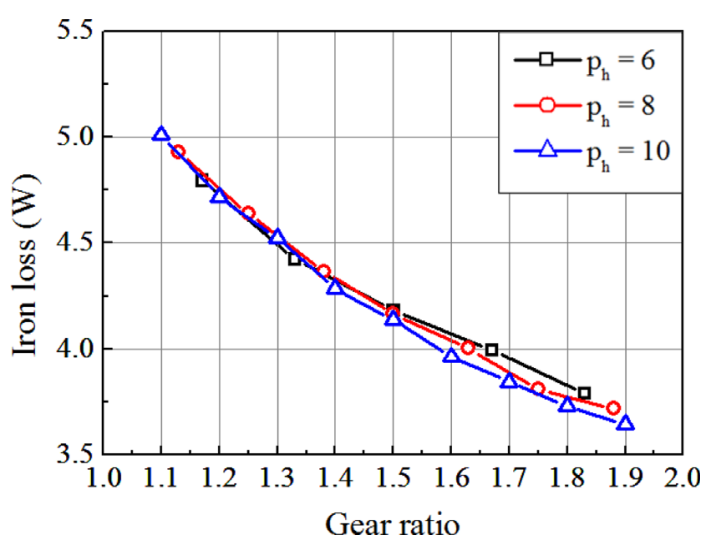

Fig. 4. (Color online) Iron losses on both rotors and modulating pieces with the variation of gear ratio for the different pole pairs of high speed rotor.

Table 2. Comparison of torque ripple on high speed rotor.

\begin{tabular}{|c|c|c|c|c|c|c|c|c|}
\hline \multicolumn{3}{|c|}{$p_{h}=6$} & \multicolumn{3}{|c|}{$p_{h}=8$} & \multicolumn{3}{|c|}{$p_{h}=10$} \\
\hline$G$ & $N_{c}$ & Rip. (\%) & G & $N_{c}$ & Rip. (\%) & $G$ & $N_{c}$ & Rip. (\%) \\
\hline 1.17 & 156 & 0.12 & 1.13 & 272 & 0.09 & 1.1 & 420 & 0.08 \\
\hline 1.33 & 84 & 1.53 & 1.25 & 144 & 0.44 & 1.2 & 220 & 0.11 \\
\hline 1.5 & 60 & 5.21 & 1.38 & 304 & 0.08 & 1.3 & 460 & 0.09 \\
\hline 1.67 & 48 & 7.83 & 1.5 & 80 & 3.57 & 1.4 & 120 & 0.67 \\
\hline 1.83 & 204 & 0.15 & 1.63 & 336 & 0.12 & 1.5 & 100 & 2.6 \\
\hline . & . & . & 1.75 & 176 & 0.17 & 1.6 & 260 & 0.2 \\
\hline . & . & . & 1.88 & 368 & 0.15 & 1.7 & 540 & 0.13 \\
\hline . & . & . & . & . & . & 1.8 & 140 & 0.54 \\
\hline . & . & . & . & . & . & 1.9 & 580 & 0.14 \\
\hline
\end{tabular}


Table 3. Iron losses on ferromagnetic materials.

\begin{tabular}{|c|c|c|c|c|c|c|}
\hline Number of $p_{h}$ & \multicolumn{2}{|c|}{6} & \multicolumn{2}{|c|}{8} & \multicolumn{2}{|c|}{10} \\
\hline Gear ratio & 1.17 & 1.83 & 1.13 & 1.88 & 1.1 & 1.9 \\
\hline Excitation frequency $(\mathrm{Hz})$ & \multicolumn{2}{|c|}{100} & \multicolumn{2}{|c|}{133.34} & \multicolumn{2}{|c|}{166.67} \\
\hline High speed rotor (W) & $\begin{array}{c}0.93 \\
(121 \%)\end{array}$ & $\begin{array}{c}0.77 \\
(100 \%)\end{array}$ & $\begin{array}{c}0.96 \\
(112 \%)\end{array}$ & $\begin{array}{c}0.86 \\
(100 \%)\end{array}$ & $\begin{array}{c}0.97 \\
(105 \%)\end{array}$ & $\begin{array}{c}0.92 \\
(100 \%)\end{array}$ \\
\hline Modulating pieces (W) & $\begin{array}{c}1.77 \\
(128 \%)\end{array}$ & $\begin{array}{c}1.38 \\
(100 \%)\end{array}$ & $\begin{array}{c}2.03 \\
(136 \%)\end{array}$ & $\begin{array}{c}1.49 \\
(100 \%)\end{array}$ & $\begin{array}{c}2.17 \\
(148 \%)\end{array}$ & $\begin{array}{c}1.47 \\
(100 \%)\end{array}$ \\
\hline Low speed rotor $(\mathrm{W})$ & $\begin{array}{c}2.09 \\
(127 \%)\end{array}$ & $\begin{array}{c}1.64 \\
(100 \%)\end{array}$ & $\begin{array}{c}1.94 \\
(142 \%)\end{array}$ & $\begin{array}{c}1.37 \\
(100 \%)\end{array}$ & $\begin{array}{c}1.87 \\
(148 \%)\end{array}$ & $\begin{array}{c}1.26 \\
(100 \%)\end{array}$ \\
\hline Total iron loss (W) & $\begin{array}{c}4.79 \\
(127 \%)\end{array}$ & $\begin{array}{c}3.79 \\
(100 \%)\end{array}$ & $\begin{array}{c}4.93 \\
(133 \%)\end{array}$ & $\begin{array}{c}3.72 \\
(100 \%)\end{array}$ & $\begin{array}{c}5.01 \\
(138 \%)\end{array}$ & $\begin{array}{c}3.64 \\
(100 \%)\end{array}$ \\
\hline
\end{tabular}

materials are saturated in all cases and there are no noticeable differences between CMG models. Furthermore, both rotors and modulating pieces have a different trend in the iron losses according to the gear ratio. Iron losses on each part of ferromagnetic materials are compared in Table 3. For the case of having same pole pairs of high speed rotor, CMG models with a low gear ratio have increased iron losses in all components, including the yoke of the high speed rotor. In general, with fixed thickness of ferromagnetic material, as the number of pole pairs is decreased, the saturation of magnetic flux can occur at the yokes of low speed rotor and modulating pieces. However, this influences even on the saturation level at the yoke of the high speed rotor having the same pole number and same excitation frequency. And it increases the iron losses. Especially, this effect is noticeable in CMG models having six pole pairs on the high speed rotor. Iron loss at high speed rotor in CMG model with a gear ratio of 1.17 is increased by $21 \%$ compared to $\mathrm{CMG}$ model with gear ratio of 1.83 .

The eddy current losses on PMs have a similar trend

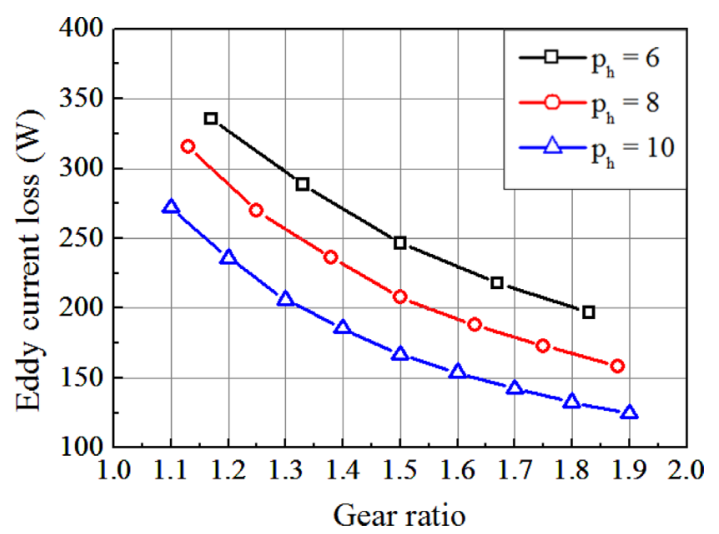

Fig. 5. (Color online) Eddy current losses on both PMs with the variation of gear ratio for the different pole pairs of high speed rotor. with iron losses as the variation of gear ratio as shown in Fig. 5. But they maintain the difference of losses between CMG models having different pole pairs regardless of gear ratio. Because the PM has almost same permeability with air and the excitation frequency of magnetic flux is constant when the speed of the high speed rotor is fixed, the dominant factor influencing on the eddy current losses is the number of PM that acts like lamination thickness. As the number of PM is increased, the eddy current losses on the PMs are reduced. Compared to the iron losses on laminated ferromagnetic materials, the eddy current losses on PMs have considerably large value, thus it needs to be reduced by dividing PM into several pieces [10].

\section{Mechanical Characteristics on the Modulating Pieces}

In $\mathrm{CMG}$, the modulating pieces experience relatively large torque corresponding to the sum of each torque acting on both rotors. Thus, the modulating pieces are subjected to high mechanical stresses that lead to deformation and contribute even mechanical failure.

The magnetic force on the modulating pieces can be calculated by using the Maxwell stress tensor [11-13]. The radial force, $F_{r}$ and tangential force, $F_{\theta}$ are given by integrating the magnetic flux densities over the surface as in (3) and (4), respectively.

$$
\begin{aligned}
& F_{r}=\frac{1}{\mu_{0}} \int_{S} \frac{B_{r}^{2}-B_{\theta}^{2}}{2} d S \\
& F_{\theta}=\frac{1}{\mu_{0}} \int_{S} B_{r} B_{\theta} d S
\end{aligned}
$$

where $B_{r}$ is the radial flux density, $B_{\theta}$ is the tangential flux density and $S$ is the surface around modulating pieces, respectively. Fig. 6 shows the radial and tangential force acting on each modulating piece in CMG models 


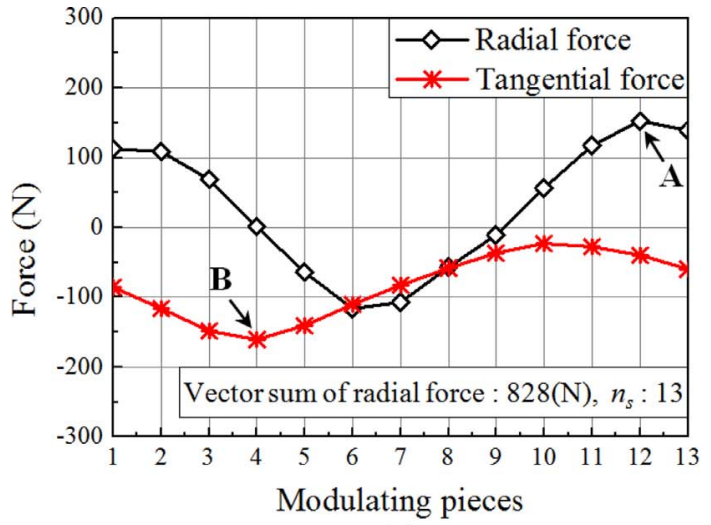

(a)

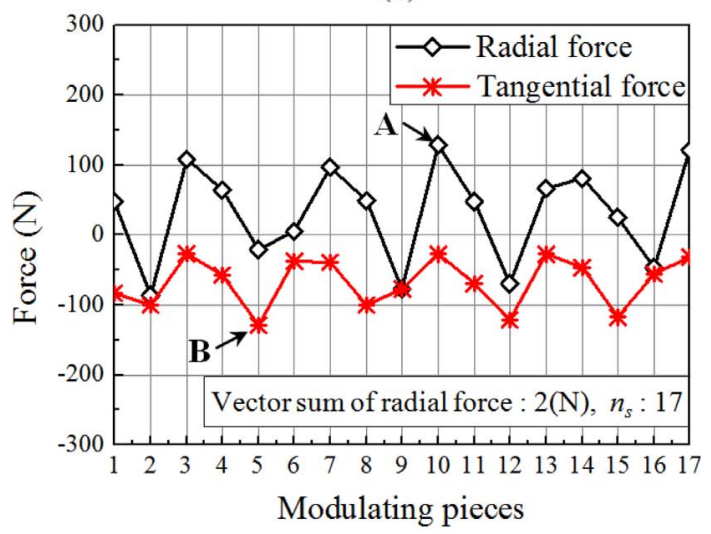

(b)

Fig. 6. (Color online) Radial and tangential force on each modulating piece with $p_{h}=6$ : (a) CMG with a gear ratio 1.17 , (b) $\mathrm{CMG}$ with a gear ratio 1.83 .

having six pole pairs on the high speed rotor. It is calculated from the Maxwell stress tensors when both rotors have a pull out torque. The label A and B indicate the modulating pieces having largest values in terms of radial and tangential forces, respectively. As shown in Fig. 6(a) of a CMG with a gear ratio of 1.17 , the largest radial and tangential forces and peak-to-peak values of forces acting on modulating pieces are larger than those of a CMG with a gear ratio of 1.83, shown in Fig. 6(b). This is because CMG models with a low gear ratio have a smaller number of modulating pieces than CMG models with a high gear ratio. However, when the $\mathrm{CMG}$ has a low gear ratio, the variation in the radial and tangential forces is smooth. When the modulating pieces are assembled into one part, total radial force acting on the part is also important. The total radial force is the vector sum of radial forces acting on each modulating pieces and its magnitude depends on the number of modulating pieces. When the CMG model has an even number of modulating pieces, it has symmetrical distribution of radial magnetic forces which are cancelled out. In contrast, when the

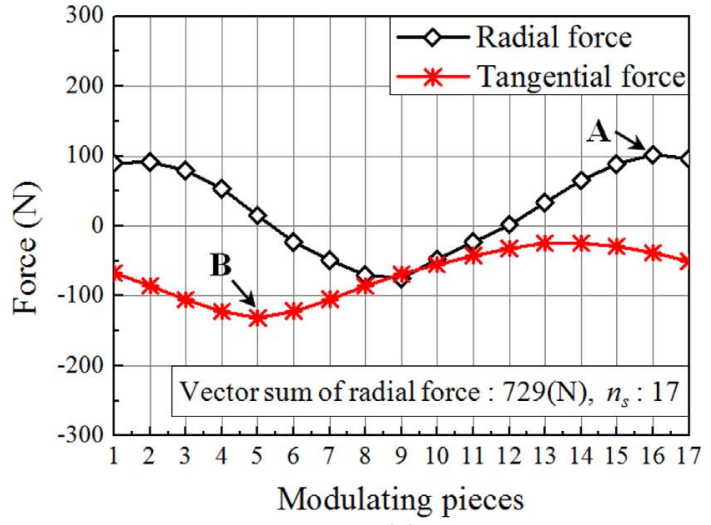

(a)

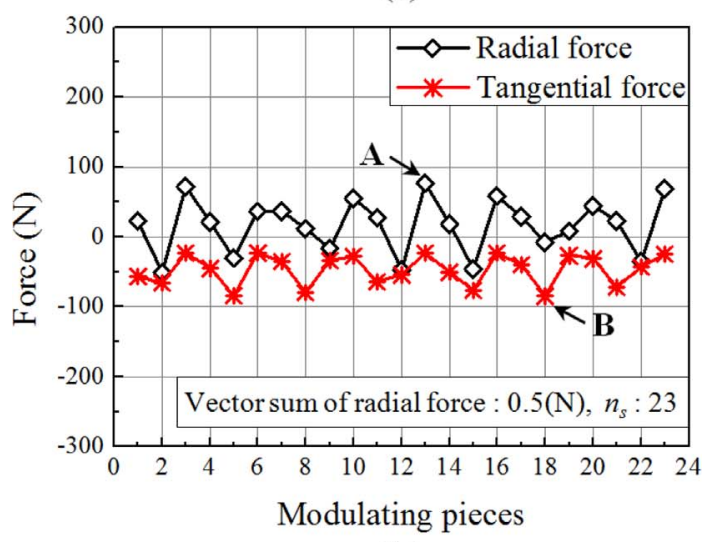

(b)

Fig. 7. (Color online) Radial and tangential force on each modulating piece with $p_{h}=8$ : (a) CMG with a gear ratio 1.13, (b) $\mathrm{CMG}$ with a gear ratio 1.88 .

CMG model has an odd number of modulating pieces, it has asymmetrical distribution of radial magnetic forces. They are not cancelled out each other. However, as the number of the modulating pieces is increased, the vector sum of radial magnetic forces is getting smaller and close to zero. These trends are same in the other CMG models having eight and ten pole pairs on the high speed rotor as shown in Fig. 7 and Fig. 8.

The modulating pieces are required to withstand the mechanical stresses caused by the magnetic forces. Table 4 shows the mechanical properties used in the structural analysis. Table 5 shows the comparison of mechanical characteristics when the largest force is acted on the modulating pieces marked as the label A and B in Fig. 6, Fig. 7 and Fig. 8. When the largest radial force is exerted on a modulating piece, the corresponding maximum normal stress and normal deformation are compared, and also, when the largest tangential force is exerted, the corresponding maximum shear stress and shear deformation are compared. All CMG models with a low gear ratio have greater values in the maximum normal stress and 


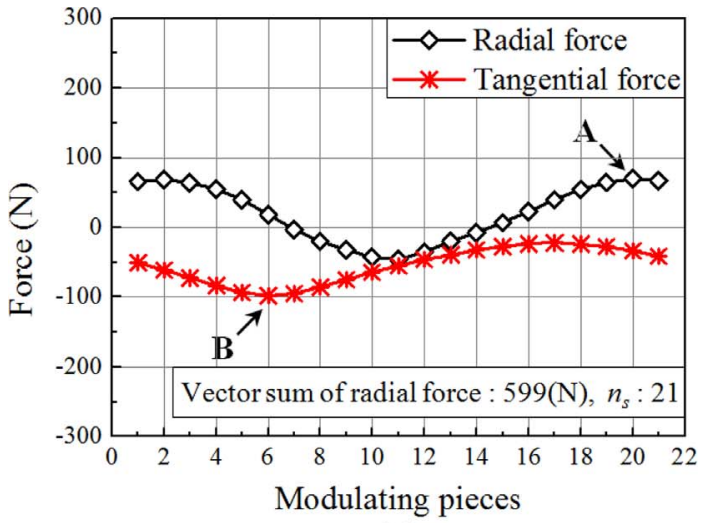

(a)

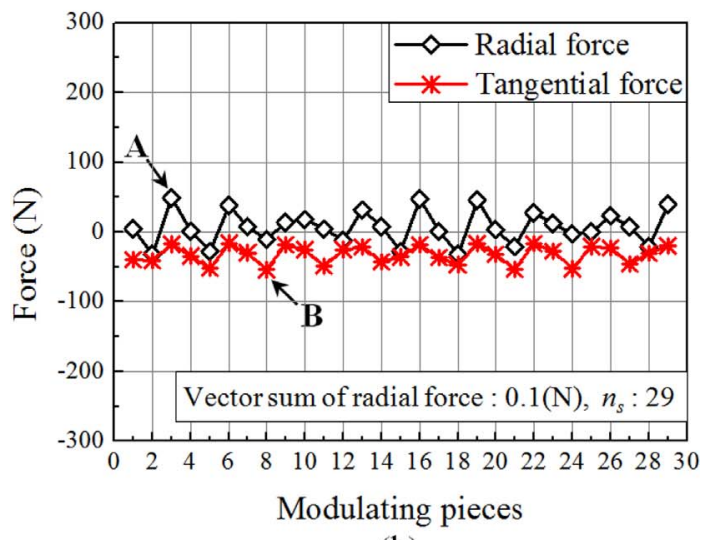

(b)

Fig. 8. (Color online) Radial and tangential force on each modulating piece with $p_{h}=10$ : (a) CMG with a gear ratio 1.1, (b) $\mathrm{CMG}$ with a gear ratio 1.9 .

normal deformation compared to $\mathrm{CMG}$ models with a high gear ratio. In contrast to CMG models with a high gear ratio, the maximum shear stresses of CMG models
Table 4. Mechanical properties of modulating pieces.

\begin{tabular}{lc}
\hline \hline Parameters & Value \\
\hline Poisson's ratio & 0.3 \\
Young's modulus $(\mathrm{GPa})$ & 200 \\
Shear modulus $(\mathrm{GPa})$ & 167 \\
Bulk modulus $(\mathrm{GPa})$ & 76.9 \\
\hline
\end{tabular}

with a low gear ratio are slightly increased, but the maximum shear deformation of them is considerably reduced. This is because the CMG models with a low gear ratio have much thicker modulating pieces in the circumferential direction than $\mathrm{CMG}$ with a high gear ratio. Furthermore, the maximum values of normal stress and normal deformation caused by the largest radial force are much larger than the maximum values of shear stress and shear deformation caused by the largest tangential force because the modulating pieces have elongated shapes along the axial direction. Thus, the normal stress and normal deformation on modulating pieces are of importance in mechanical characteristics of CMG, and the modulating pieces should be designed to withstand large radial forces. The $\mathrm{CMG}$ with a low gear ratio also needs to be a more robust structure compared to that of a $\mathrm{CMG}$ with a high gear ratio.

A material is said to start yielding when its equivalent stress reaches a critical value known as the yield point. The equivalent stress is a function of normal and tangential stresses and it is used to predict yielding of materials under loading condition [14]. As shown in Table 5, when the CMG models have low gear ratio and small number of pole pairs on the high speed rotor, they have a tendency to get big equivalent stress. The contribution of

Table 5. Comparison of mechanical characteristics on modulating pieces.

\begin{tabular}{|c|c|c|c|c|c|c|c|c|c|c|c|c|}
\hline \multirow{3}{*}{$\begin{array}{l}\text { Case } \\
\text { Number of } P_{h} \\
\text { Gear ratio }\end{array}$} & \multicolumn{6}{|c|}{$\begin{array}{c}\text { Case of maximum radial force on } \\
\text { modulating pieces }(\mathrm{A})\end{array}$} & \multicolumn{6}{|c|}{$\begin{array}{l}\text { Case of maximum tangential force on modulating } \\
\text { pieces (B) }\end{array}$} \\
\hline & \multicolumn{2}{|c|}{6} & \multicolumn{2}{|c|}{8} & \multicolumn{2}{|c|}{10} & \multicolumn{2}{|c|}{6} & \multicolumn{2}{|c|}{8} & \multicolumn{2}{|c|}{10} \\
\hline & 1.17 & 1.83 & 1.13 & 1.88 & 1.1 & 1.9 & 1.17 & 1.83 & 1.13 & 1.88 & 1.1 & 1.9 \\
\hline Max. radial force $(N)$ & 151.9 & 129.6 & 101.6 & 76.9 & 69.9 & 49 & 1.0 & -20.3 & 15.1 & -7.6 & 18.3 & -11 \\
\hline Max. tangential force $(\mathrm{N})$ & -40.1 & -27.5 & -38.1 & -23.3 & -33.3 & -17.5 & -160.7 & -129.5 & -131.3 & -84.9 & -97.9 & -54.3 \\
\hline Max. normal stress (MPa) & $\begin{array}{c}13.56 \\
(117 \%)\end{array}$ & $\begin{array}{l}11.64 \\
(100 \%)\end{array}$ & $\begin{array}{l}11.86 \\
(125 \%)\end{array}$ & $\begin{array}{c}9.50 \\
(100 \%)\end{array}$ & $\begin{array}{l}10.91 \\
(141 \%)\end{array}$ & $\begin{array}{c}7.75 \\
(100 \%)\end{array}$ & & & & & & \\
\hline Max. shear stress (MPa) & . & . & . & & · & • & $\begin{array}{c}0.39 \\
(105 \%)\end{array}$ & $\begin{array}{c}0.37 \\
(100 \%)\end{array}$ & $\begin{array}{c}0.37 \\
(103 \%)\end{array}$ & $\begin{array}{c}0.36 \\
(100 \%)\end{array}$ & $\begin{array}{c}0.34 \\
(103 \%)\end{array}$ & $\begin{array}{c}0.33 \\
(100 \%)\end{array}$ \\
\hline Max. normal deformation $(\mu \mathrm{m})$ & $\begin{array}{c}1.66 \\
(118 \%)\end{array}$ & $\begin{array}{c}1.41 \\
(100 \%)\end{array}$ & $\begin{array}{c}1.43 \\
(132 \%)\end{array}$ & $\begin{array}{c}1.08 \\
(100 \%)\end{array}$ & $\begin{array}{c}1.2 \\
(145 \%)\end{array}$ & $\begin{array}{c}0.83 \\
(100 \%)\end{array}$ & . & . & & - & . & . \\
\hline Max. shear deformation $(\mu \mathrm{m})$ & . & . & . & 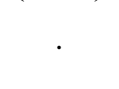 & . & 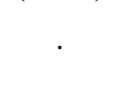 & $\begin{array}{l}0.36 \\
(71 \%)\end{array}$ & $\begin{array}{c}0.51 \\
(100 \%)\end{array}$ & $\begin{array}{c}0.53 \\
(79 \%)\end{array}$ & $\begin{array}{c}0.67 \\
(100 \%)\end{array}$ & $\begin{array}{c}0.63 \\
(84 \%)\end{array}$ & $\begin{array}{c}0.75 \\
(100 \%)\end{array}$ \\
\hline Max. equivalent stress (MPa) & $\begin{array}{c}32.5 \\
(116 \%)\end{array}$ & $\begin{array}{c}28.1 \\
(100 \%)\end{array}$ & $\begin{array}{c}28.2 \\
(123 \%)\end{array}$ & $\begin{array}{c}22.9 \\
(100 \%)\end{array}$ & $\begin{array}{c}23.9 \\
(128 \%)\end{array}$ & $\begin{array}{c}18.7 \\
(100 \%)\end{array}$ & $\begin{array}{c}13.5 \\
(69 \%)\end{array}$ & $\begin{array}{c}19.5 \\
(100 \%)\end{array}$ & $\begin{array}{c}17.5 \\
(99 \%)\end{array}$ & $\begin{array}{c}17.7 \\
(100 \%)\end{array}$ & $\begin{array}{c}19.1 \\
(109 \%)\end{array}$ & $\begin{array}{c}17.6 \\
(100 \%)\end{array}$ \\
\hline
\end{tabular}


the tangential force is not much greater as that of normal force on the equivalent stress of the modulating pieces.

\section{Conclusion}

This paper analyzes the electromagnetic and mechanical characteristics of $\mathrm{CMG}$ with a low gear ratio for the applications of counter rotating mechanism. For the selected number of pole pairs of high speed rotor, torque characteristics, iron losses and mechanical performances are compared. As the gear ratio is getting closer to 1 , both iron losses on the ferromagnetic materials and eddy current losses on the rotor PMs are increased. In all CMG models with a low gear ratio, the modulating pieces are subjected to greater radial and tangential forces compared to those with a high gear ratio regardless of the number of pole pairs on high speed rotor. As the modulating pieces have an elongated shape in the axial direction, the normal stress and normal deformation on modulating pieces are of importance in the mechanical characteristics of CMG and radial forces have the dominant effect on the equivalent stress.

\section{Acknowledgment}

This research was supported by Basic Science Research Program through the National Research Foundation of Korea (NRF) funded by the Ministry of Education, Science and Technology (NRF-2012R1A1A2044307).

\section{References}

[1] K. J. Paik, S. B. Suh, and H. H. Chun, KSOE 14, 36 (2000).

[2] Y. Inukai and F. Ochi, Proceeding of the first International Symposium on Marine Propulsors (SMP09) 112 (2009).

[3] K. S. Min, B. J. Chang, and H. W. Seo, International journal of Naval Architecture and Ocean Engineering 1, 29 (2009).

[4] L. Moroz, P. Pagur, Y. Govorushchenko, and K. Grebennik, Proceeding of International Symposium on Heat Transfer in Gas Turbine Systems, DOI 10.1615/390 (2009).

[5] S. N. Jung, T. S. No, and K. W. Ryu, Renewable Energy 30, 631 (2005).

[6] K. Atallah and D. Howe, IEEE Trans. Magn. 37, 2844 (2001).

[7] K. Atallah, S. D. Calverley, and D. Howe, IEE ProcElectr. Power Appl. 151, 135 (2004).

[8] N. W. Frank and H. A. Toliyat, Proceeding of IEMDC 1224 (2009).

[9] D. J. Evans and Z. Q. Zhu, Proceeding of IEMDC 1403 (2011).

[10] P. Zheng, J. Bai, J. Lin, Z. Fu, Z. Song, and F. Lin, J. Appl. Phys. 115, 17E706 (2014).

[11] T. Tarnhuvud and K. Reichert, IEEE Trans. Magn. 24, 443 (1988).

[12] L. Frosini and P. Pennacchi, Proceeding of IECON 1287 (2006).

[13] K. J. Meessen, J. J. H. Paulides, and E. A. Lomonova, IEEE Trans. Magn. 49, 536 (2013).

[14] N. E. Dowling, Mechanical Behavior of Materials (4/E), Prentice Hall (2013) pp. 257-305. 